Folia Toruniensia - Toruń 2015 r., t. 15

\title{
Marlena Hałas
}

Wojewódzka Biblioteka Publiczna - Książnica Kopernikańska w Toruniu

Nicolaus Copernicus Public Provincial Library in Toruń

Öffentliche Woiwodschaftsbibliothek - Kopernikus Bücherei in Toruń

e-mail:mh@ksiaznica.torun.pl

\section{aport z działalności Dyskusyjnych}

\section{Klubów Książki koordynowanych przez}

\section{Wojewódzką Bibliotekę Publiczną -}

\section{Książnicę Kopernikańską w Toruniu}

\section{w pierwszej połow ie $2015 \mathrm{r}$.}

Program Dyskusyjne Kluby Książki realizowany jest przez wojewódzkie biblioteki publiczne w całej Polsce przy wsparciu finansowym i merytorycznym Instytutu Książki. Program funkcjonuje od 2007 r. Adresowany jest do czytelników poszukujących miejsca, w którym można porozmawiać o książkach. Celem Klubów jest przede wszystkim ożywienie środowisk skupionych wokół bibliotek oraz zachęcenie bibliotekarzy do kreowania mody na czytanie. Koordynatorem programu DKK w województwie kujawsko-pomorskim, w podregionie toruńsko-włocławskim jest Wojewódzka Biblioteka Publiczna - Książnica Kopernikańska.

\section{Dane ogólne}

a. Dyskusyjne Kluby Książki

\begin{tabular}{|l|l|c|}
\hline \multicolumn{1}{|c|}{ Liczba Dyskusyjnych Klubów Książki } & \multicolumn{1}{|c|}{ Ogółem } & $\mathbf{6 7}$ \\
\hline \multirow{2}{*}{ w tym klubów dla } & dorosłych & 50 \\
\cline { 2 - 3 } & dzieci i młodzieży & 17 \\
\hline \multirow{3}{*}{ w tym klubów działających na terenie gmin } & miejskich & 46 \\
\cline { 2 - 3 } & miejsko-wiejskich & 0 \\
\cline { 2 - 3 } & wiejskich & 21 \\
\hline
\end{tabular}

b. Spotkania w ramach Dyskusyjnych Klubów Książki

\begin{tabular}{|l|l|c|}
\hline Liczba spotkań Dyskusyjnych Klubów Książki & \multicolumn{1}{|c|}{ Ogółem } & $\mathbf{2 3 8}$ \\
\hline \multirow{2}{*}{ w tym klubów dla } & dorosłych & 181 \\
\cline { 2 - 3 } & dzieci i młodzieży & 57 \\
\hline
\end{tabular}


c. Uczestnicy Dyskusyjnych Klubów Książki

\begin{tabular}{|c|c|c|}
\hline $\begin{array}{c}\text { Liczba osób uczestniczących w spotkaniach } \\
\text { DKK }\end{array}$ & Ogółem & 2006 \\
\hline \multirow{2}{*}{ w tym klubów dla } & dorosłych & 1444 \\
\hline & dzieci i młodzieży & 562 \\
\hline $\begin{array}{c}\text { Średnia liczba osób uczestniczących } \\
\text { w spotkaniach DKK }\end{array}$ & Ogółem & 8,4 \\
\hline \multirow{2}{*}{ w tym klubów dla } & dorosłych & 7,9 \\
\hline & dzieci i młodzieży & 9,9 \\
\hline Liczba stałych członków DKK & Ogółem & 563 \\
\hline \multirow{2}{*}{ w tym klubów dla } & dorosłych & 395 \\
\hline & dzieci i młodzieży & 168 \\
\hline
\end{tabular}

d. Zakupione książki do Dyskusyjnych Klubów Książki

\begin{tabular}{|c|c|c|c|c|c|}
\hline Liczba zakupionych książek & Ogółem & \multirow{3}{*}{ Tytuły } & 57 & \multirow{3}{*}{ Woluminy } & 547 \\
\hline \multirow{2}{*}{ w tym do klubów dla } & dorosłych & & 49 & & 519 \\
\hline & dzieci i młodzieży & & 8 & & 28 \\
\hline
\end{tabular}

\section{Najczęściej omawiane książki}

a. Literatura piękna (w porządku alfabetycznym wg tytułu książki)

\begin{tabular}{|c|l|l|}
\hline 1 & Balladyny i romanse & Karpowicz Ignacy \\
\hline 2 & Bokserka & Plebanek Grażyna \\
\hline 3 & Domek nad morzem & Ulatowska Maria \\
\hline 4 & Grand & Wiśniewski Janusz L. \\
\hline 5 & Grecka mozaika & Cygler Hanna \\
\hline 6 & Posłaniec & Zusak Markus \\
\hline 7 & Sońka & Karpowicz Ignacy \\
\hline 8 & Trociny & Varga Krzysztof \\
\hline 9 & Wśród swoich & Oz Amos \\
\hline 10 & Zbrodniarz i dziewczyna & Witkowski Michał \\
\hline
\end{tabular}

b. Literatura faktu (w porządku alfabetycznym wg tytułu książki)

\begin{tabular}{|c|l|l|}
\hline 1 & $\begin{array}{l}\text { 20 lat nowej Polski w reportażach według } \\
\text { Mariusza Szczygła }\end{array}$ & Szczygieł Mariusz (wybór) \\
\hline 2 & Awantury na tle powszechnego ciążenia & Lem Tomasz \\
\hline 3 & $\begin{array}{l}\text { Człowiek o twardym karku. Historia } \\
\text { księdza Romualda Jakuba Wekslera- } \\
\text { Waszkinela }\end{array}$ & Rosiak Dariusz \\
\hline 4 & Hanka Bielicka: umarłam ze śmiechu & Korpolewski Zygmunt \\
\hline 5 & Miedzianka. Historia znikania & Springer Filip \\
\hline 6 & Nic nie zdarza się przypadkiem & Terzani Tiziano \\
\hline 7 & Proszę bardzo & Rottenberg Anda \\
\hline 8 & Taka jestem i już & Zawadzka Magdalena \\
\hline 9 & Towarzyszka panienka & Jaruzelska Monika \\
\hline 10 & Tak kochali Galicjanie & Wernichowska Bogna \\
\hline
\end{tabular}


c. Literatura dla dzieci i młodzieży (w porządku alfabetycznym wg tytułu książki)

\begin{tabular}{|c|l|l|}
\hline 1 & Alicja w krainie czarów & Carroll Lewis \\
\hline 2 & Asiunia & Papuzińska Joanna \\
\hline 3 & Czarna owieczka & Grabowski Jan \\
\hline 4 & Czy wojna jest dla dziewczyn? & Beręsewicz Paweł \\
\hline 5 & Dzień Matki & Świerczyńska Anna \\
\hline 6 & Europa pełna baśni & Laskowska Joanna \\
\hline 7 & Mity dla dzieci & Kasdepke Grzegorz \\
\hline 8 & O soli cenniejszej niż złoto & Dobšinsky Pavol \\
\hline 9 & Psoty i kłopoty wróbelka Elemelka & Łochocka Hanna \\
\hline 10 & Słoneczne jajo & Beskow Elsa \\
\hline
\end{tabular}

\section{Najczęściej czytani autorzy}

a. Literatura piękna (w porządku alfabetycznym wg nazwiska autora)

\begin{tabular}{|c|l|}
\hline 1 & Bator Joanna \\
\hline 2 & Cabre Jaume \\
\hline 3 & Dehnel Jacek \\
\hline 4 & Karpowicz Ignacy \\
\hline 5 & Miłoszewski Zygmunt \\
\hline 6 & Picoult Jodi \\
\hline 7 & Stasiuk Andrzej \\
\hline 8 & Ulatowska Maria \\
\hline 9 & Varga Krzysztof \\
\hline 10 & Wiśniewski Janusz L. \\
\hline
\end{tabular}

b. Literatura faktu (w porządku alfabetycznym wg nazwiska autora)

\begin{tabular}{|c|l|}
\hline 1 & Jagielska Grażyna \\
\hline 2 & Koper Sławomir \\
\hline 3 & Kuźniak Angelika \\
\hline 4 & Michniewicz Tomek \\
\hline 5 & Springer Filip \\
\hline 6 & Szczygieł Mariusz \\
\hline 7 & Szejnert Małgorzata \\
\hline 8 & Tochman Wojciech \\
\hline 9 & Rottenberg Anda \\
\hline 10 & Urbanek Mariusz \\
\hline
\end{tabular}

c. Literatura dla dzieci i młodzieży (w porządku alfabetycznym wg nazwiska autora)

\begin{tabular}{|c|l|}
\hline 1 & Beręsewicz Paweł \\
\hline 2 & Beskow Elsa \\
\hline 3 & Carroll Lewis \\
\hline 4 & Gevalda Anna \\
\hline 5 & Kasdepke Grzegorz \\
\hline 6 & Grabowski Jan \\
\hline 7 & Maleszka Andrzej \\
\hline 8 & Pałasz Marcin \\
\hline 9 & Papuzińska Joanna \\
\hline 10 & Tyszka Agnieszka \\
\hline
\end{tabular}




\section{Nowi autorzy książek zakupionych do Dyskusyjnych Klubów Książki:}

a. Literatura piękna (w porządku alfabetycznym wg nazwiska autora)

\begin{tabular}{|c|l|}
\hline 1 & Elton Ben \\
\hline 2 & Enerlich Katarzyna \\
\hline 3 & Guzowska Marta \\
\hline 4 & Littell Jonathan \\
\hline 5 & Satrapi Marjane \\
\hline
\end{tabular}

b. Literatura faktu (w porządku alfabetycznych wg nazwiska autora)

\begin{tabular}{|c|l|}
\hline 1 & Cieślar Artur \\
\hline 2 & Czyńska Małgorzata \\
\hline 3 & Nowak Szymon \\
\hline 4 & Pryzwan Mariola \\
\hline 5 & Winnicka Ewa \\
\hline
\end{tabular}

c. Literatura dla dzieci i młodzieży (w porządku alfabetycznym wg nazwiska autora)

\begin{tabular}{|l|l|}
\hline 1 & Lockhart E. \\
\hline 2 & Mitgutsch Ali \\
\hline 3 & Napp Daniel \\
\hline 4 & Warda Małgorzata \\
\hline 5 & Wechterowicz Przemysław \\
\hline
\end{tabular}

\section{Spotkania autorskie}

\begin{tabular}{|c|l|c|l|c|}
\hline Lp. & $\begin{array}{c}\text { Nazwisko i imię } \\
\text { autora }\end{array}$ & \multicolumn{1}{|c|}{ Data } & \multicolumn{1}{|c|}{ Nazwa biblioteki } & $\begin{array}{c}\text { Liczba uczestni- } \\
\text { ków spotkania }\end{array}$ \\
\hline 1 & Paweł Beręsewicz & 10.03 .2015 & $\begin{array}{l}\text { Miejska Biblioteka Publiczna } \\
\text { we Włocławku }\end{array}$ & 56 \\
\hline 2 & Paweł Beręsewicz & 11.03 .2015 & $\begin{array}{l}\text { Gminna Biblioteka } \\
\text { Publiczna w Dębowej Łące }\end{array}$ & 48 \\
\hline 3 & Paweł Beręsewicz & 11.03 .2015 & $\begin{array}{l}\text { Wojewódzka Biblioteka } \\
\text { Publiczna - Książnica } \\
\text { Kopernikańska w Toruniu, } \\
\text { filia nr 7 }\end{array}$ & 73 \\
\hline 5 & Jacek Dehnel & 23.03 .2015 & $\begin{array}{l}\text { Powiatowa i Miejska } \\
\text { Biblioteka Publiczna } \\
\text { w Chełmży }\end{array}$ & 14 \\
\hline 6 & $\begin{array}{l}\text { Jokek Dehnel } \\
\text { Jędrzejewska- }\end{array}$ & 23.03 .2015 & $\begin{array}{l}\text { Wojewódzka Biblioteka } \\
\text { Publiczna - Książnica } \\
\text { Kopernikańska w Toruniu }\end{array}$ & 60 \\
\hline 7 & 23.03 .2015 & $\begin{array}{l}\text { Wojewódzka Biblioteka } \\
\text { Publiczna - Książnica } \\
\text { Kopernikańska w Toruniu, } \\
\text { filia nr 2 }\end{array}$ & $\begin{array}{l}\text { Miejska Biblioteka Publiczna } \\
\text { w Chełmnie }\end{array}$ \\
\hline Jacek Dehnel & 24.03 .2015 & 43 \\
\hline
\end{tabular}




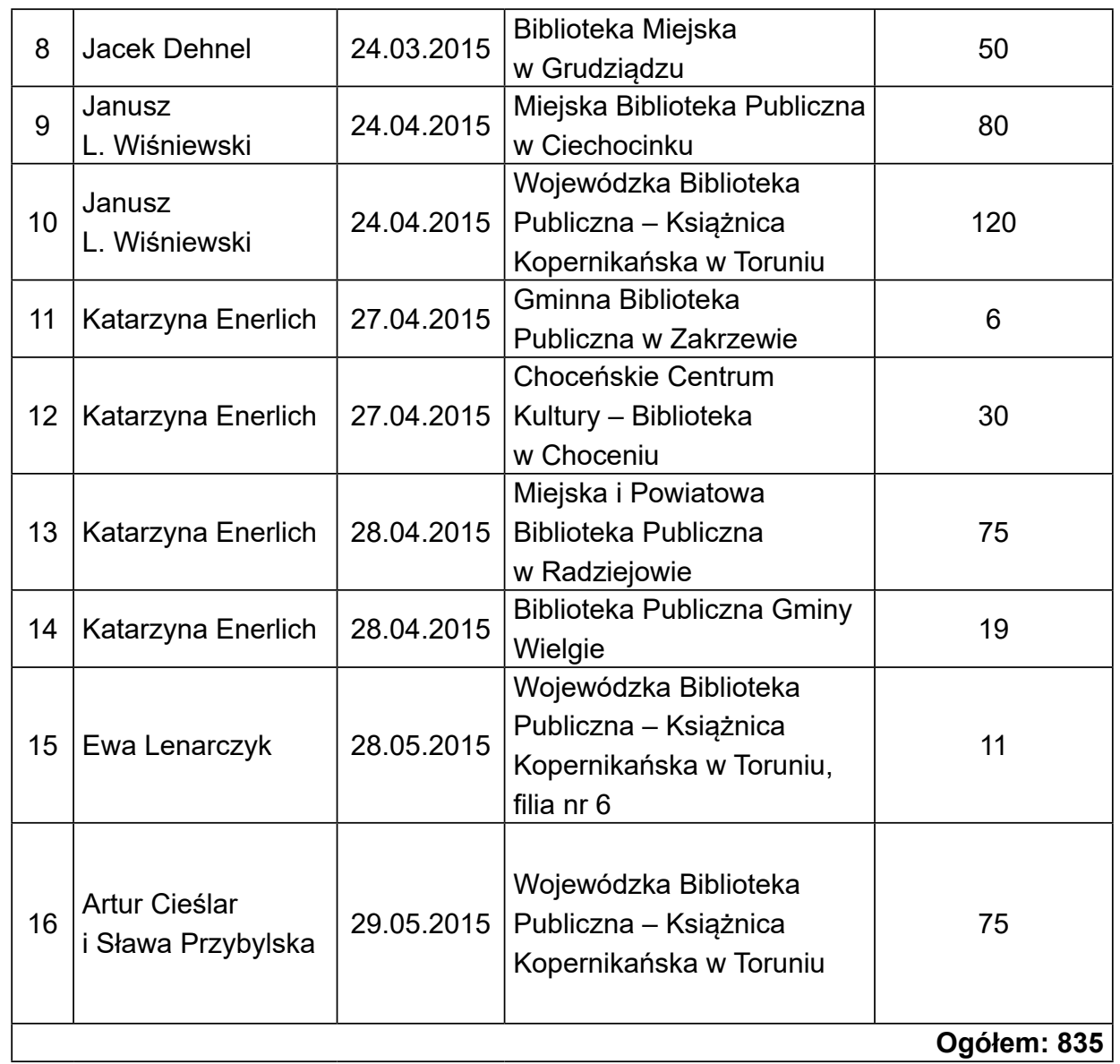

